\title{
Los maestros en Guadalajara: proceso depurador y entorno rural (1936-1939)
}

\author{
Amparo Pont SAstre
}

\section{RESUMEN}

El objetivo de este artículo es hacer un breve análisis cualitativo sobre la depuración de los maestros en la provincia de Guadalajara. El tema se centra en el entorno rural y tiene en cuenta varios factores: el

entorno geográfico, que contempla la peculiar división de

la provincia en dos zonas -republicana y nacionat durante todo el conflicto civil; la actitud de los maestros, su ideología, sus relaciones y la conflictividad del pueblo donde les tocó ejercer; la

opinión de las autoridades locales -civiles y eclesiásticas- a la hora de informar sobre su conducta profesional, particulary social; y el criterio seguido por las comisiones depuradoras que fueron, al fin y al cabo, las encargadas de proponer la sanción o confirmación del maestro.

\section{ABSTRACT}

The goal that this article pursues is making a brief qualitative analysis of the purge of teachers in the province of Guadalajara. The theme is focused on the country, and it pays attention to some factors: the geography, that shows us that the area was divided into two zones -the Republic zone and the National zone- until the end of the Civil War; techers'attitude, their ideology, their relationships with the village where they where teaching, and the conflicts of these villages; the opinion of the local powers -civil and eclesiastic powers- about the proffesional, private and social behaviour of the teacher; and the point of view of the purging comissions, because, after all, the proposal of sanction or confirmation to the teacher concerned to them. 


\section{INTRODUCCIÓN}

La Guerra Civil española marcó una línea divisoria entre vencedores y vencidos y dejó una huella difícil de borrar que sólo fue capaz de suavizar el paso del tiempo. El Nuevo Régimen así lo propició cuando puso en marcha un proceso depurador capaz de purificar todos los ámbitos de la vida profesional, y perpetuó la represión más allá de los límites que en un principio hubieran sido previsibles. Entre los destinatarios de este proceso se encontraban los maestros -colectivo especialmente vulnerable en época de conflictos políticos por su implicación en la educación y la socialización del pueblo- a los que el Nuevo Estado confirmó, sancionó o separó definitivamente de su profesión con el fin de limpiar el magisterio de aquellos que habian actuado contra los principios de toda educación ${ }^{1}$. Los confirmados serían los encargados de educar al pueblo según las directrices ideológicas diseñadas por el Régimen. Se efectuó un giro tajante en el campo pedagógico y los maestros pasaron, de servir al individuo y guiarle en su proceso formativo, a servir al Estado. Dejaron a un lado la transmisión del conocimiento para hacer hincapié en el aprendizaje de los valores considerados tradicionales que, firmemente conectados con la doctrina católica, eran considerados por el Régimen propios del talante español. Su difusión, por medio de consignas ideológicas ultraconservadoras, propició la formación de ciudadanos disciplinados, sumisos y desmovilizados. La enseñanza, con la represión y la censura, pasó a convertirse en uno de los mejores instrumentos de control social desarrollándose dentro de un estrecho margen intelectual.

Son varios los historiadores que en estos últimos años han investigado la represión franquista y, dentro de ésta, la depuración del magisterio. Los estudios realizados alcalzan un número importante de provincias españolas que es preciso completar para llegar a una aproximación global. Uno de los trabajos más completos es el de Francisco Morente Valero ${ }^{2}$ que, a través del análisis de catorce provincias $y$, apoyándose en una amplia base documental, nos aproxima a los resultados de la depuración a nivel nacional.

Este artículo tiene por objeto hacer un breve análisis cualitativo sobre la depuración del maestro rural en una de las provincias que aún no ha sido estudiada: Guadalajara. Su estudio, además de apoyar la idea generalizada de que el colectivo de los maestros no se significó políticamente, pretende:

1 A.H.N. Causa General. Legajo 1070/2 Informe sobre el desarrollo de la Enseñanza y estado de las Escuelas en la Provincia de Guadalajara.

2 Morente Valero, Francisco. La depuración del Magisterio Nacional (1936-1943) Edi. Ámbito, Valladolid, 1997. 
a) diferenciar distintas zonas dentro de la provincia para poner de manifiesto la situación peculiar por la que atraviesa ésta durante el conflicto.

b) establecer tipologias o agrupaciones de maestros atendiendo a determinadas características: ideología política, religiosidad, zona donde se encuentra, etc.

c) determinar qué otros factores contribuyeron a que el maestro fuera sancionado.

Para ello se ha utilizado una documentación valiosísima que se encuentra en el AGA 3: Los pliegos de descargo elaborados por el propio maestro. Son historias de vida de un colectivo que intentó hacer frente en el mundo rural, a los problemas de la vida cotidiana agravados por la guerra. Los expedientes del AGA aportan no sólo la versión del maestro, sino la de sus vecinos y conocidos -amigos y enemigos- y la de las autoridades del pueblo donde había ejercido. Son historias contrapuestas descritas desde distintos ángulos y desde posturas enfrentadas.

\section{GUADALAJARA: ENTORNO GEOGRÁFICO Y MAPA ESCOLAR}

Guadalajara, una situación peculiar. Guadalajara es una provincia territorialmente grande, con más de cuatrocientos pueblos, con poca industria en 1936 y por tanto eminentemente rural. La mayoria de sus pueblos no superaban los mil habitantes, pero en casi todos ellos existía alguna escuela (había alrededor de ochocientas aunque muchas eran sólo pequeños locales sin las mínimas condiciones) con un maestro y una maestra, ya que a pesar de la instauración de la coeducación por la República, los niños y las niñas seguian, en gran medida, separados.

El Boletín de la FETE de Guadalajara 4 editaba una nota de la Inspección en la que se recordaba a los maestros la obligación de poner en marcha la coeducación en todas las Escuelas Nacionales, prueba de que ésta aún no se había implantado en la mayor parte de la provincia.

3 Archivo General de la Administración. Documentación perteneciente al Archivo Central de Educación y Ciencia (ACME)

4 A.H.N. Causa General. Legajo 1070/2. Boletín de la FETE. Guadalajara 5 febrero de 1938. Hace referencia a dos órdenes de 9 y 11 de septiembre de 1937 sobre la coeducación. 
En un informe realizado en 1939 , delegados de FET y de las JONS analizaban las tendencias políticas predominantes en la provincia. Según ellos, era mayoritario el pensamiento derechista aunque existían liberales nostálgicos (romanonistas, en términos generales personas con más cuarenta años) ocultos bajo una capa de tradicionalismo. La implantación de FET y de las JONS, casi nula antes del conflicto, aumentó paulatinamente en la zona liberada a partir de 1938 y 1939, mientras que en Molina -pequeño feudo del tradicionalismo- su implantación resultaba más difícil.

Con la llegada de la República fueron cuatro los diputados elegidos para las Constituyentes. Dos de ellos pertenecían al partido socialista, uno a Acción Republicana y otro era independiente. Eso demuestra que durante la República en la capital y en determinados pueblos, los habitantes apoyaban en buena medida a los partidos republicanos y de izquierda y se sabe que durante el conflicto funcionó de forma muy completa la organización Socorro Rojo Internacional.

Su situación geográfica, su división en zona republicana y nacional y la permanencia del frente de guerra en su territorio a lo largo de los años que duró el conflicto, contribuyeron a crear en la provincia una situación peculiar. En ella podemos distinguir tres zonas:

1. Zona nacional. Es la que queda desde el primer momento de la sublevación (dias o unos pocos meses) en manos de los nacionales. Es la parte norte y en ella se encuentran Molina de Aragón y Sigüenza. La primera, vivió con menor intensidad la violencia popular republicana, pues su adhesión al bando nacional se da casi de inmediato, mientras que la segunda, al ser un núcleo de fuerte implantación religiosa y derechista sufre en un corto espacio de tiempo una dura represión sangrienta.

2. Zona republicana/nacional. La que estando en manos republicanas al principio, es conquistada por los rebeldes en 1937. La línea del frente pasa de la zona antes citada, a la altura de Brihuega, dejando casi la totalidad del partido de Molina en manos del ejercito rebelde. La variación del frente, con pequeños avances y retrocesos a partir de esta fecha, será mínima. Los habitantes serán testigos de la violencia incontrolada de los primeros meses; deberán hacer frente a la presión de las milicias republicanas y a la de los rebeldes y el funcionariado (entre ellos los maestros) deberá afrontar una primera depuración, la republicana, que en determinados casos cuando se produzca la franquista, los datos y avales aportados se utilizarán en su contra.

5 A.G.A. Presidencia. Caja 24. Informe Político de la provincia de Guadalajara. 
3. Zona republicana. La que estuvo en manos de la República hasta el final del conflicto. Comprendía la capital y toda la parte sur que limita con la provincia de Madrid. Fue una zona en la que la población, además de vivir -como las anteriores- toda la violencia que entraña un conflicto, se vio obligada a demostrar constantemente adhesión a una ideología radicalizada que, en muchos casos, no compartía o le era indiferente.

\section{DEPURACIÓN Y CONTROL DE LA RETAGUARDIA}

A medida que avanzaba el conflicto ambos bandos intentaban ganar la guerra y controlar la retaguardia. Se inició una dura represión para someter al pueblo y eliminar a desafectos e indiferentes que incluía la depuración de todo el funcionariado 6 y, entre ellos, la del magisterio. El colectivo que ejercía en la zona republicana sufrió dos tipos de depuración: la primera llevada a cabo por República y la segunda por el bando nacional con la toma y liberación de territorios. Este proceso tuvo resultados distintos.

De la primera se tienen pocos datos. El maestro debía rellenar un cuestionario y declarar cual era su postura ideológica, cómo apoyaba a la República y aportar avales de personas leales y afectas al gobierno del Frente Popular. Los considerados desafectos fueron cesados y aunque no existen cifras sobre los mismos, un informe realizado en 1942 por la Inspección franquista 7 sobre el desarrollo de la enseñanza republicana en Guadalajara en tiempo de guerra, hace mención a esta depuración en los siguientes términos:

Fueron numerosas las sanciones según Orden Ministerial de 2 de septiembre de 1936; pero admitidas las reclamaciones y estimadas en gran parte en mayo del 37 aparecieron los fallos definitivos en número muy inferior. La sanción fue generalmente el traslado, traslados que no siempre figuraron como disposición oficial. Los 50 maestros propietarios e interinos que han cobrado haberes no percibidos en esta época indican el número de los destituidos, jubilados y no presentados incurriendo en abandono de destino (...) No así los trasladados que casi siempre suponía la persecución. No es posible concretar el número de éstos.

6 Crespo Redondo, Jesús. Purga de maestros en el Guerra Civil. Ed. Ámbito. Valladolid. 1987. (págs. 17-18). El autor, cita y analiza la orden emanada de las autoridades nacionales, de 19 de agosto de 1936 que establecía la depuración de todos los funcionarios públicos.

7 A.H.N. Causa General. Legajo 1072/2. Informe sobre el desarrollo de la Enseñanza y el estado de las Escuelas en Guadalajara a partir de 1936, realizado por la Inspección en 1942. 
Son, según el informe, cincuenta los maestros que no ocupan, al estallar la guerra, sus plazas en la provincia de Guadalajara. Teniendo en cuenta que muchos de ellos, cuando se produce el alzamiento están de vacaciones en la zona ocupada por los nacionales y no pueden o no quieren incorporarse a la parte republicana, es evidente que esta primera depuración no fue especialmente dura.

La segunda depuración fue más compleja ya que se sometió a los interesados, primero, a un juicio popular - no siempre coherente y sinceroy segundo, al jerárquico que, apoyado en la normativa creada y tomando como base la información partidista e interesada del sector vencedor, dio lugar a sanciones injustas y arbitrarias. Fue una depuración pedagógica 8 que tenia dos finalidades: el castigo ejemplar y la prevención de la disidencia. Fue un método represivo eficaz destinado a lograr el sometimiento del magisterio, ya que no sólo sirvió para apartar a los considerados desafectos, si no también para aclarar el servicio incondicional que éste debía prestar al Estado. Las sanciones tuvieron consecuencias económicas y psicológicas dramáticas para una parte del colectivo sancionado, que se vio humillado y empobrecido al no poder ejercer la profesión que constituía su único medio de vida. Lo dicho queda reflejado en la súplica de un maestro de Sigüenza que pide a la Comisión que tenga a bien solucionar su caso de suspensión provisional...

Este funcionario-maestro Ilmo. Sr., que no contaba con otros medios económicos que los procedentes de su cargo oficial, quedando, por consiguiente, sumido en la más espantosa miseria con su mujer y tres hijas entre los 9 y 18 años edad teniendo que relegar su dignidad personal y profesional durante año y medio para no perecer materialmente de hambre... ${ }^{9}$

Pero es necesario ir más allá de lo que significó y conllevó para los maestros el represivo y humillante proceso depurador. Existen situaciones complejas y peligrosas que las personas deben resolver en el acto o en pocos días, presiones por parte de las autoridades locales a las que hay que hacer frente, equívocos, prejuicios y rumores que circulan entre los vecinos del pueblo. Todo ello agravado por las visitas de milicianos que llegan al pueblo armados, impartiendo órdenes, registrando y confiscando bienes y que, ante la inminente llegada de los nacionales obligan a

8 Morente Valero, Francisco. La Depuración del Magisterio Nacional (1936-1943). Ed. Ámbito. Madrid. 1997. En esta obra el autor menciona y analiza en la segunda parte el porqué de esta depuración pedagógica.

9 A.G.A. Educación. Depuración de Maestros. Legajo 186. Expediente de un maestro de Sigüenza. 
los habitantes a abandonar la población. El maestro es, en muchos casos, la única persona de relieve en agrupaciones rurales de escasísima importancia que tendrá que tratar con los que llegan al pueblo y su actuación será vista por sus gentes de muy distintas formas.

Por tanto, es preciso desentrañar cómo se desarrollaba la vida cotidiana de un maestro en tiempos de guerra en un bando que quizás no eligió $y$ en un ambiente rural, a veces hostil, en el que era un forastero y se le miraba con recelo. ¿Cómo le afectaron las luchas caciquiles o venganzas personales? ¿Cómo sobrevivió en una situación tan compleja como la que vivió Guadalajara en los años 1936-1939?

Si el maestro ha sido una persona de ideas avanzadas y ha implantado en su escuela el proyecto de enseñanza republicano, será acusado de izquierdista, de trasmitir la ideología en la escuela y atentar contra las ideas de religión, patria y moral. La cosa será más grave si ha estado afiliado a algún organismo, partido o sindicato del Frente Popular; si ha hecho propaganda o a si ha apoyado directa o indirectamente la rebelión. Cualquier actuación (palabra, obra u omisión) que no entre dentro de los postulados político-religiosos y sociales del Nuevo Régimen será motivo de denuncia y sanción. Los expedientes del A.G.A. aportan pequeñas historias donde la denuncia, el resentimiento, la envidia y la venganza están presentes pero también la solidaridad y en algunos casos, actitudes heroicas.

\section{EL PROYECTO DE ENSEÑANZA REPUBLICANO}

Para investigar el tema de la depuración del magisterio -tanto en Guadalajara como en otras provincias- es necesario remontarse a las reformas que en materia de enseñanza quiso poner en marcha la II República. Ésta, en 1931, se enfrentaba a una gran falta de escuelas, a un alto índice de población sin escolarizar y a un profesorado muy poco cualificado. Su propósito era claro: llevar a cabo un proyecto innovador capaz de ofrecer una alternativa a la enseñanza tradicional -considerada por muchos arcaica- con el fin de erradicar el analfabetismo, culturizar al pueblo y educar, como decía María Zambrano, para la libertad. Para ello era necesario dignificar la profesión de maestro, crear nuevas escuelas y mejorar la calidad de la enseñanza que debía ser laica, gratuita, obligatoria y estar en manos del Estado. Se proponía conseguir la neutralidad ideológica, implantar la coeducación y utilizar métodos didácticos no memorísticos. 
Para ello se fomentó la enseñanza al aire libre y el contacto con la naturaleza y se dieron competencias a los gobiernos de las regiones autónomas para que el aprendizaje en las escuelas pudiera realizarse en la lengua materna. La escuela tenía que estar abierta a todos, independientemente de su condición social, creencias religiosas y políticas. Se utilizó el término Escuela Unificada para definirla, con un sentido estrictamente pedagógico, con el fin de hacer referencia a la unidad de todo el proceso, desde la escuela a la universidad. Sería la capacidad para el estudio lo primordial, no las posibilidades económicas 10.

Para conseguir sus objetivos el gobierno republicano consideró necesario reformar los estudios de Magisterio, cambiar la forma de acceso al cuerpo de maestros nacionales y proyectar la construcción de escuelas en todo el territorio nacional. Rodolfo Llopis, en un artículo publicado en Crisol el 16 de abril de 1931 hablaba del problema educativo al que debia hacer frente la República: era un problema no sólo de cantidad, sino también de calidad y ponía el énfasis en la labor docente, destacando que debian hacerse maestros nuevos 11. En la Revista de Pedagogía Lorenzo Luzuriaga dejaba sentado que había que educar republicanamente porque la república se salvaría por la Escuela.

Pero esta reforma dio lugar al enfrentamiento Iglesia-República, ya que la primera, que tenía en sus manos el monopolio de la enseñanza lo pierde. Al implantarse el laicismo sólo se le reconocerá a la Iglesia ... el derecho, sujeto a inspección del Estado, de enseñar sus respectivas doctrinas en sus propios establecimientos.

Estas reformas fueron criticadas por la derecha, el Ejército y la Iglesia ${ }^{12}$. La enseñanza de la religión dejaba de ser obligatoria en la escuela y el maestro podía, por razones de conciencia, negarse a darla. En este caso la enseñanza pasaba a ser competencia del párroco que debía impartirla, según la ley, en sus establecimientos. El nuevo proyecto dio lugar a la llamada guerra escolar, un enfrentamiento entre el maestro y el párroco que se extendió a los símbolos. El retrato de Alfonso XIII fue sustituido por la bandera republicana y desaparecieron de las aulas los crucifijos e imágenes religiosas. Se dejó de rezar y cantar him-

10 Luis Martín, Francisco de. Historia de la FETE (1909-1936), Fondo de Enseñanza. 1997 (págs. 30)

11 BarReiro Ródriguez, Hermínio. Lorenzo Luzuriaga y la renovación Educativa en España (1.889-1936) Edictos do Castro, A Coruña (págs. 86)

12 Morente Valero, Francisco. La Depuración del Magisterio Nacional (1936-1943). Ed. Ámbito. Madrid. 1977. (págs. 69-69) 
nos religiosos y éstos fueron sustituidos durante la guerra por otros de tipo republicano-marxita.

\section{EL MAESTRO, LA ESCUELA Y LA ENSEÑANZA EN GUADALAJARA EN TIEMPO DE GUERRA}

Los boletines de la FETE muestran la situación en que se encuentran los maestros con la guerra y el estado de la escuela en el mundo rural en 1937:

En Guadalajara y su provincia hay más maestros que escuelas vacantes, como consecuencia del repliegue hacia nuestro campo de los compañeros, cuyos pueblos fueron invadidos por el conglomerado del ejercito "nacional" 13.

Ante esta situación, se pide a los maestros que pasen a otras provincias en las que se da el caso contrario, que dejen de pensar que son maestros de tal o cual localidad y tomen conciencia de que lo son de la España leal y deben ocupar la plaza que se les señale ... sin reparar en las incomodidades ni en los peligros.

Pero no sólo se les pide a los maestros que cambien de localidad, sino también que se afilien a partidos 0 a organizaciones sindicales. Eso se hace desde el boletín del siguiente modo:

¿Eres independiente? ¿no militas en ningún partido político, en alguna organización sindical? En estos tiempos en que vivimos esta postura es muy sospechosa. O estás con la República, o estás en contra de ella. Defínete y camina al ritmo dei verdadero pueblo ${ }^{14}$.

El maestro se verá obligado en determinados casos a ir al frente a engrosar las filas de los combatientes o a formar parte de los milicianos de la cultura. En su pliego de descargo explicará cómo intentó eludir ciertas presiones y escapar del alistamiento.

En el boletín se analiza también el estado de la escuela rural. Dice así:

Hay una diferencia grandisima entre la escuela de poblaciones grandes y la escuela rural y que es absurdo, a mi juicio legislar al unísono para ambas. La vida, la psicología, la necesidad, etc, etc., son muy distintas y a ellas hay que atenerse...

13 A.H.N. Causa General. Legajo 1070/2. Boletín de la FETE. Guadalajara 18 de mayo de 1937.

14 A.H.N. Causa General. Legajo 1070/2. Boletín de la FETE. Guadalajara 18 de mayo de 1937. 
Hace una crítica a la escuela de los años monárquicos y dictatoriales para pasar a recordar en qué quedaron las 27.000 escuelas que en reducidisimo tiempo pensaba crear la República. Y añade:

... pero ¿que pasó? Que mientras en Madrid y otras capitales se creaban magníficos grupos (...) en los pueblos no podían funcionar por falta de local y en otras tenían que cerrarlas por ser locales inhabitables (...) estamos convencidos de que muchísimas de las escuelas que por los pueblos hay, sólo tienen de escuelas, eso: el nombre; pues son en su mayoria inmundas, zahurdas, sin luz ni ventilación, donde el maestro va dejando su salud y los niños no sienten ni pueden sentir cariño a la escuela... ${ }^{15}$

En cuanto a la enseñanza, el Frente Popular consideró primordial la lucha contra el analfabetismo y la puesta en marcha de la coeducación. Se preparó una primera campaña en las zonas rurales con alto porcentaje de analfabetos y se organizó el régimen de coeducación para admitir en las escuelas alumnos de uno y otro sexo.

El órgano editorial de la FETE propugnaba la utilización de la cultura como instrumento de guerra e instaba a los que por la edad no podían empuñar las armas, a sumarse al movimiento revolucionario, a ser militar sin dejar de ser maestro y culturizar al pueblo.

Sin embargo, en el informe que elabora la Inspección franquista sobre la enseñanza en Guadalajara 16 se reconoce que en las escuelas, los maestros no utilizaron la cultura para aleccionar políticamente ni a niños ni a adultos (prueba de que las presiones no debieron ser tan grandes) ni tampoco propiciaron sentimientos antirreligiosos ni anticlericales y que en todo caso las enseñanzas se decantaron hacia la concienciación social:

En lo fundamental, apenas vario, durante el periodo de la guerra, el régimen y organización escolar establecido a través de la época republicana.

Considera que lo que se intentaba era ... infundir en los niños el sentido de lo que llamaron la lucha del pueblo con los ideales de su democracia marxista y el odio a todo lo que significaba el Movimiento Nacional, por medio de lecciones, fiestas y motivos ocasionales. La ola de odio religioso y de brutales instintos desatados en el ambiente de crimen y libertinaje social y moral, fueron la lección más grave y eficaz contra los

15 A.H.N. Causa General. Legajo 1070/2. Boletín de la FETE. Guadalajara 18 de mayo de 1937.

16 A.H.N. Causa General. Legajo 1070/2. Informe sobre el desarrollo de la Enseñanza y el Estado de las Escuelas en Guadalajara. 
principios de toda educación. Pero añade algo clarificador que los pliegos de descargos de los maestros depurados confirman:

Fue general por parte del profesorado, la intención de restar influjo y fuerza a este poder del ambiente y a sus violencias, replegándose en el trabajo escolar al plano de la instrucción, aunque el temor o condescendencia y contemporización con la situación en unos y el propio sentir de los menos, impidiera seguir constantemente esta norma ${ }^{17}$.

En materia religiosa el informe refleja que ... no aparece oficialmente la persecución de las creencias religiosas en la enseñanza primaria más que de una manera indirecta y con la pantalla del laicismo, mientras sobresale la orientación político-social.

Estas conclusiones serán las mismas que reflejarán los pliegos de descargos elaborados por los maestros a la hora de hacer frente a unas acusaciones comunes a casi todos ellos como las de ... orientar la educación y la enseñanza en sentido izquierdista y con pretexto de laicismo atacar las ideas de Religión, Patria y Moral. Pero la Comisión Depuradora, que dictará las primeras sanciones definitivas en mayo de 1940, hará caso omiso a sus alegaciones y dará crédito antes que al maestro a los informantes y delatores.

\section{TIPOLOGÍA DE MAESTROS DEPURADOS}

El maestro rural en Guadalajara, si tomamos como referencia los pliegos de descargos, tiene un nivel cultural más que aceptable dentro del entorno que vive y realiza su actividad. Lee habitualmente la prensa y en algunos casos escribe y publica artículos relacionados con su profesión. Conoce la actualidad, sabe de movimientos y tendencias políticas y conoce la legislación republicana en materia de enseñanza que le llega, habitualmente, por medio de la revista Magisterio Español. Por ello, niega y cuestiona con conocimiento de causa a la Comisión Depuradora los cargos que se le imputan. No es anticlerical, aunque no cumpla con el precepto dominical. Está acostumbrado al trato con los distintos grupos y clases sociales de su entorno; y su comportamiento, salvo excepciones, es considerado correcto. Sus detractores serán los que se han visto rele-

17 Esta afirmación, recogida en el informe anterior, resulta del todo sorprendente si tenemos en cuenta que la Causa General se instruyó para demostrar la culpabilidad de la República en el conflicto civil. 
gados del poder, tienen ocultos intereses o se han visto suplantados en sus funciones por el maestro. Ellos denunciarán que participó en mítines, fue un elemento perturbador de la paz del pueblo, izquierdista e irreligioso. Antiguos caciques, cura párroco y algunos vecinos, no soportaron su visión crítica de la realidad y sus comentarios sobre el ámbito social y político por moderados que fueran. A pesar de ello, los datos muestran que en Guadalajara, al igual que en otras provincias españolas, el maestro no fue un individuo politizado ni radicalizado ${ }^{18}$. Sus preferencias a la hora de afiliarse se mueven entre Izquierda Republicana y el Partido Socialista.

Establecer una tipología de maestros depurados es limitar la variedad de matices que éstos poseen y que dejan traslucir los distintos expedientes. Sin embargo, existen en ellos cualidades y actitudes que se repiten y que propician una determinada actuación dependiendo de la ideología político-religiosa del individuo y la zona donde se encuentra. Se producen cambios y adaptaciones por necesidad y en función de la gravedad de la situación. Podemos establecer, simplificando mucho, los siguientes tipos atendiendo a su ideología política o a la que les es atribuida por el Nuevo Régimen:

1.a) Conservadores en la zona nacional. Los que siendo ideológicamente conservadores (afiliados o no a partidos de derechas) o neutrales y católicos practicantes, apoyaron desde el primer momento la Causa Nacional y pudieron demostrar que habian tenido una conducta acorde a la propugnada por el Nuevo Estado, desde 1934. Tenían, además, buenas relaciones y contactos con las autoridades franquistas y fueron considerados por éstas como afectos y gentes de orden. En zona nacional estos maestros no tuvieron problemas y fueron confirmados en sus cargos.

1.b) Conservadores en la zona republicana. Si por el contrario, el maestro citado anteriormente se encontraba en zona republicana/nacional o republicana, se enfrentaba, dependiendo del grado de derechismo (que le atribuyeran autoridades, comités, milicianos, delatores, etc.) a la muerte, la cárcel, al cese o a un estrecho marcaje que iba a obligarle a dar un giro a su ideología. Ante el grado de conflictividad del entorno se vio obligado, en muchos casos, a aparentar una radicalidad ideológica que no compartía y actuó de acuerdo con los postulados del Frente Popular. Todo ello

18 Fernández Soria, J. M; Agullo, M." Carmen. Maestros Valencianos bajo en franquismo. Ed.Diputació de València, Institució Alfons e! Magnànim. Valencia1999. Estos autores establecen un perfil del maestro valenciano depurado y coinciden con otros investigadores en que el colectivo de los maestros no estuvo, en general, ideologizado ni comprometido. 
para no levantar sospechas y evitar ser denunciado. Algunos se implicaron en exceso (destrucción de símbolos religiosos e iglesias, etc.) y su conducta, con la liberación, fue causa de denuncias y penalizada con la máxima sanción. Es el caso de un maestro de Cabanillas del Campo. El alcalde informa sobre su conducta y dice:

Lo ha sido de verdadero hipócrita por manifestarse como elemento de derechas, con los que ha convivido diariamente y su actuación lo ha sido de muy distinta forma, pues al estallar el Glorioso Movimiento Nacional, se destapó, separándose de aquellos elementos y con todo entusiasmo se unió a los marxistas ${ }^{19}$.

Otros cargos serán: haber fundado en Guadalajara el S.R.I 20 y la organización de los Niños Pioneros. La explicación de su actuación la da el propio maestro en los siguientes términos:

Apenas iniciado el Movimiento, fui perseguido por ser corresponsal de A.B.C., Blanco y Negro, Jeromín y Ya. Desde septiembre de 1925, hasta el día que estalló el Movimiento, haber sido secretario de la Junta de Unión Patriótica en este pueblo, el 27 y 28 votar en todas las elecciones a la derecha ${ }^{21}$ (...)

Niega haber fundado el S.R.I y la organización de los Niños Pioneros. Se afilió al Socorro Rojo ... obligado por un miliciano de Madrid, el cual era mi perseguidor, puesto que fijó su residencia con la familia en el pueblo. Fue este miliciano, el que según el maestro, fundó los Niños Pione$\operatorname{ros}^{22} \mathrm{y}$ al tener uno de sus hijos en la escuela ... se presentaba en cualquier momento, incluso armado de pistola y fusil, pueden decirlo los niños y tal vez el vecino... Manda su testimonio desde la prisión Central de Guadalajara el 26 se octubre de 1939. Es sancionado con la separación definitiva y baja en el escalafón.

2.a) Progresistas en la zona nacional. En este grupo se incluyen los que, afiliados o considerados por los informantes simpatizantes del Fren-

19 A.G.A. Educación. Legajo 186. Depuración de maestros. Informe del alcalde de Cabanillas del Campo..

20 Socorro Rojo Internacional.

21 A.G.A. Educación. Legajo 186. Pliego de descargo del maestro de Cabanillas del Campo.

22 Los llamados «Pioneros» eran niños encuadrados en una organización de tipo político que según el citado informe sobre la enseñanza en Guadalajara, tenían entre sus cometidos ejercer la vigilancia sobre maestros y compañeros. El informe que recoge la Causa General dice que servia... de poderosos medio difusor irresponsable y de elemento policiaco... Sin embargo, según Francesca Wilson en uno de sus relatos "La colonia-granja de Crevillente" dice que son una especie de Boy Scouts del Frente Popular. En Ve y Cuenta lo que pasó en España de Aranzazu Usandizaga, Planeta, Barcelona, 2000. (p. 174) 
te Popular, quedaron desde el principio del conflicto en zona nacional y tuvieron que hacer frente a un proceso depurador primero provisional y más tarde definitivo, en el que, a pesar de negar los cargos e intentar camuflar su tendencia anterior (afiliándose a FET y JONS, alistándose al ejercito nacional, participando en las milicias ciudadanas etc.) fueron sancionados con dureza, siendo algunos cesados definitivamente. Eran momentos propicios para apartar a estos maestros, por medio de informes y denuncias, de los cargos que habian ocupado con la victoria del Frente Popular y frenar su acceso a puestos de responsabilidad político-administrativa en el Nuevo Estado. En el mundo rural, los ajustes de cuentas y venganzas personales quedaron, en muchos casos, ocultas bajo el manto de la ideología política. Es el caso del maestro de Alpedroches un pueblo situado en la zona norte de Guadalajara. El maestro, acusado de izquierdista, expone en su defensa:

Si fuese izquierdista, me hubiera pasado al campo rojo, como lo hicieron otros funcionarios (...) cuando el mes de agosto de 1936 llamó el gobierno de la República a los maestros de la provincia, teniendo en cuenta que esta localidad está enclavada en una zona que en los primeros momentos era visitada indistintamente por los rojos y por los nacionales...

Recordará a la Comisión que ... cuando en las proximidades de Alpedroches hubo una incursión roja oculté en mi casa a la furia roja los objetos de culto de la Iglesia de dicho pueblo... ${ }^{23}$ Sin embargo, la acusación más grave a la que se enfrenta el maestro es la de haberse casado civilmente (signo de antirreligiosidad y de izquierdismo) y por ello será sancionado con la separación definitiva y baja en el escalafón. El maestro lejos de caer en el desánimo, se casará por la iglesia, ingresará en FET y de las JONS obteniendo el carnet de afiliado definitivo y asistirá a los cursillos de Orientación y Perfeccionamiento del Magisterio. Aportará pruebas (bibliografía utilizada, cuadernos de los niños, etc.) y avales de militantes de FET y de las JONS y pedirá la revisión, que en 1947 le será concedida siendo readmitido en el cargo. Otros maestros en circunstancias parecidas se afiliarán también a FET y de las JONS y encontrarán en sus filas apoyo y avales con los que suavizar sanciones e incluso serán rehabilitados en sus cargos.

2.b) Progresistas en la zona republicana. En este grupo se dan varios casos. Por un lado encontramos a afiliados con cierta antigüedad que eran los menos, pues el colectivo, en general, no estaba significado políticamente. Otros se afiliaron a la FETE de forma obligatoria y masiva en

23 A.G.A. Educación. Ləgajo 186. Pliego de descargo del maestro de Alpedroches. 
1936 con el alzamiento. Los maestros que pertenecían a partidos del Frente Popular o eran considerados afectos, obtuvieron cargos y mejoraron su situación (cargos políticos, administrativos, mejores plazas, etc.) y por ello algunos, al final de la guerra, se exiliaron o se autodepuraron. Otro grupo, aparentemente sin una ideología clara, optó por afiliarse -forzosa o voluntariamente- al estallar la guerra, con el único motivo de mantener su empleo y salvar su vida. Muchos contribuyeron, desde su posición ventajosa, a salvar vidas ajenas y a calmar los ánimos en momentos de gran tensión. Su actuación fue menospreciada y no reconocida por el Régimen que no tuvo en cuenta los informes favorables (aportados incluso desde el sector vencedor) a la hora de suavizar las sanciones. Una vez en zona nacional fueron cesados provisionalmente, para serlo en algunos casos, definitivamente al final del conflicto. La Comisión Depuradora los juzgó si cabe con más severidad que a otros.

El maestro de Villarejo de Medina en su hoja de depuración roja declaró pertenecer a la Agrupación Socialista afecta a UGT, desde la organización del Frente Popular local. Fue sancionado con la separación definitiva y pidió la revisión en 1942. El Juzgado Superior de Revisiones propuso una rebaja de la sanción, que quedaría en suspensión de empleo y sueldo por un año, traslado fuera de la provincia e inhabilitación para cargos directivos y de confianza. Basó su petición en las contradicciones de los informantes. El alcalde y el padre de familia defendian su actuación con estas palabras:

«Evitó que la Iglesia Parroquial fuese incendiada por los rojos consiguiéndolo» 24

3. Neutrales. Es el grupo donde encajan personas de muy variado comportamiento. Sin una ideología determinada, los maestros de este grupo, vieron en lo legislado por la República (social y culturalmente) el modo de despertar, en un mundo rural atrasado e inmovilista, el deseo de libertad y justicia. No pertenecían a organizaciones ni partidos políticos pero aplicaron la normativa impuesta y adoptaron formas de vida más libre y menos condicionadas por la tradición: comprendieron que el laicismo era una opción y algunos no se casaron por la Iglesia, y no bautizaron a sus hijos; preconizaron la necesidad de un reparto más justo de la riqueza, tanto material como cultural; ayudaron a los que estaban en peligro en momentos difíciles, etc. Otros por el contrario eran creyentes, colaboraron en el mantenimiento del Culto y el Clero y no se implicaron

24 A.G.A. Educación. Legajo 187. Depuración de maestros. Expediente del maestro de Villarejo de Medina. Informe del Juzgado Superior de Revisiones. 
políticamente, pero la comprensión de la situación y su forma de vida fue considerada izquierdista por no adaptarse al orden social tradicional exigido por el Nuevo Régimen. Se preocuparon, a pesar de las presiones y limitaciones, de ejercer su profesión con dignidad. Todos ellos estuvieron en la zona republicana/nacional o republicana y fueron o fingieron ser afectos a la República pero vieron con horror el desarrollo del conflicto y las atrocidades cometidas. Se preocuparon por protegerse, salvar sus vidas y las de los suyos, porque así lo requería la situación y el momento no permitía pensar que más tarde tendrian que responder por ello. Algunos, por sus años y corresponderle a su quinta, pasaron a engrosar las filas del ejército republicano. A este grupo sin duda pertenece una gran mayoría de los sancionados temporalmente. Sin embargo, un maestro que encaje en este grupo llamado neutral, puede pasar a engrosar (desde el punto de vista del régimen) el de conservador o progresista al entrar en juego otros factores capaces de alterar su situación. Entre ellos: la conflictividad del pueblo y el tipo de relaciones mantenidas (en tiempo de guerra) con la parte vencedora del conflicto. Los componentes de esta última serán, al fin y al cabo, los que definan cual ha sido la actitud del maestro y establezcan que relación ha tenido con lo sucedido en el pueblo.

\section{OTROS FACTORES QUE INCIDEN EN EL PROCESO DEPURADOR}

Como ya ha quedado apuntado anteriormente, otros factores entran en juego a la hora de clasificar y sancionar al maestro. Además de la ideología político-religiosa del individuo, la zona donde ejerce y su actuación, hay que tener también en cuenta: el grado de conflictividad del pueblo; el entorno familiar y social del maestro; el peso del factor religioso y predisposición del párroco hacia su persona; la opinión de las autoridades locales y su deseo de ajustar cuentas o de volver a la normalidad cuanto antes, así como la calidad de los avales que aporte el maestro. Es importante también que éste no haya aceptado cargos, ni mejorado económicamente. De este modo la Comisión Depuradora considerară que no fue privilegiado por las autoridades republicanas y deducirá que no prestó servicio a su causa.

1. Grado de conflictividad político-social del pueblo. Para conocer cómo se desarrollaba la vida del maestro durante el conflicto debemos analizar con mucha atención el pliego de descargos que este elabora y remite a la comisión. En él, además de exponer los hechos, sitúa a la co- 
misión en el contexto rural y escenifica pormenores de su destino en los que deja traslucir la conflictividad social que vive el pueblo. La maestra de Renera antes de pasar a negar y a justificar su actuación abre un apartado que titula Algo de historia en el que dice así:

Cuando yo vine a este pueblo, a principios de 1935, hacía poco que habia ocurrido un asesinato, mejor dicho, dos. A consecuencia de este hecho, se hallaba el pueblo dividido en dos partidos con odios muy enconados. En el primer tiempo, los principales representantes de ambos partidos se mostraron muy amables al objeto, sin duda, de atraerme cada uno al suyo. Como yo, falta de experiencia, procuré estar a bien con todos sin agregarme a ninguno de los dos; cuando se convencieron de esto, todos se disgustaron y lo que yo había creído mejor surtió el efecto contrario: el quedar mal con todos. Las autoridades rojas se vengaron durante la guerra suprimiendo la gratificación de la casa-habitación, elevando el impuesto de utilidades y obligándome a entregarles $\mathrm{mi}$ aparato de radio 25 .

El maestro de Drieves cuenta una historia caciquil mas truculenta que no debió gustar nada a la comisión pues fue cesado definitivamente aunque readmitido en 1946 al serle aceptada la solicitud de revisión de su expediente. Afiliado a Izquierda Republicana describe un altercado que pone de manifiesto la lucha por el poder en el pueblo. Había acompañado a visitar - en las elecciones de 1931- el colegio electoral a unos comunistas y narra lo sucedido

IFatal día aquell El pueblo fanatizado, engañado y dominado por $D$. Gonzalo Sánchez, hijo de la familia que aquí dominaba todo, ayudado por los subcaciques después de una gran campaña anterior a las elecciones en que solo se les enseñaba a estos aldeanos errores que como sociedad esclavizada iban a donde se les dirigía, ciegos de ira y rencor por creer que el que suscribe iba en contra de los principios básicos de sus creencias e ideas políticas siempre achuchado por el magno cacique que no me doblegaba a sus caprichos como los demás súbditos... 26

Se lamenta de que el cacique pusiera en su contra al pueblo. No le hicieron daño, pero le insultaron gravemente y recuerda cómo meses antes celebraban su llegada al pueblo ... !ya tenemos maestro! decían. Reconoce ... haber sido durante el domino rojo secretario de Incautaciones nombrado por UGT que aquí funciona con Izquierda Republicana y que efectivamente se formuló la incautación de unas fincas ... pero dándole un

25 A.G.A. Educación. Legajo 187. Depuración de maestros. Expediente de la maestra de Renera. Pliego de descargo.

26 A.G.A. Educación. Legajo Depuración de maestros. Expediente del maestro de Drieves. Pliego de descargo. 
cierto carácter para que fuera escudo contra las demasias de las milicias que aquí llegaban para saciar sus apetitos siendo salvaguarda esta fórmula. Aporta las firmas de los colonos que le avalan diciendo que en ningún tiempo quedaron las fincas bajo el yugo de la incautación y que pudieron realizar sus operaciones con entera libertad. Las fincas aparecian como incautadas pero a los dueños se le pagaban las rentas. Una nota interna de la comisión, que incluye la petición de revisión, dice así:

Lucha y caciquería de pueblo existe desde luego en este expediente. No es que el maestro estuviera quieto. También tiene lo suyo y se metió donde no debió entrar pero dada su edad, más de 62 años, y teniendo en cuenta el aval del Sr. Cura Párroco que antes y después del Movimiento dice que cumplió siempre con los deberes de Católico, que pagaba el culto y que es un buen maestro, pese a las faltas de ortografía que existen en los descargos. Vista la propuesta de la Comisión, la inmediata inferior a la separación, el tiempo que lleva sancionado con la separación y el no haber sido sentenciado, lo que indica que las incautaciones no dejaron amargura ni sedimento en el pueblo y debió ser una comedia lo del Comité... puede hacérsele una revisión aplicándole la sanción que propuso la comisión (suspensión de empleo y sueldo durante dos años, traslado de escuela, con prohibición de no pedir vacantes en dos años e inhabilitación).

Esta descripción nos muestra varias características típicas a tener en cuenta sobre las decisiones la comisión: El peso de la opinión del cura, el paso del tiempo que permite su readmisión, el paternalismo ante la edad y una buena dosis de cinismo al reconocer que desde el principio todo fue un montaje. La postura del maestro al confraternizar con los oponentes del cacique del pueblo de valió la enemistad de éste y sus secuaces, que con el fin del conflicto, contribuirian a que fuera sancionado con la máxima pena.

2. Peso del factor religioso, cuyo protagonista es el cura Párroco. En la mayoría de los casos su informe es determinante. Muchos maestros deben su sanción precisamente al no cumplimiento de los preceptos religiosos y a no haber acudido a la iglesia durante su permanencia en el pueblo. Y aunque no siempre informa sobre lo que conoce y da por sentadas suposiciones e informes partidistas de vecinos agraviados, todo empeora cuando ha habido muertes de por medio.

El párroco de La Toba hace un informe sobre la maestra de Pinilla de Jadraque en los siguientes términos:

No la conozco personalmente pero puedo asegurar por referencias dignas de crédito de mi compañero el párroco de Pinilla, asesinado por los rojos, que 
son extremadamente izquierdistas, ella, su marido y los hijos. Muchas veces se lamentaba mi difunto compañero con amargura de la campaña antirreligiosa que hacia la Sra. Maestra, y su marido era persona que divulgaba ideas muy avanzadas en sentido izquierdista entre los vecinos del pueblo intentando o llevando a su efecto la fundación de la casa del pueblo 27.

El cura se hace eco de las críticas de su compañero, alude a la familia de la maestra y menciona la fundación de la Casa del Pueblo que, aunque no sabe con seguridad si la fundaron o no, la cita para hacer más consistente su denuncia. Añade:

Lo que puedo asegurar con certeza absoluta es que la Sra. Maestra y su familia, saquearon la parroquia pues en su domicilio una vez liberado ese pueblo (yo iba con las fuerzas libertadoras) encontramos ornamentos de la parroquia completamente hechos pedazos, además encontramos libros antirreligosos y mucha prensa izquierdista.

El entorno familiar tendrá un peso importante a la hora de agravar las sanciones.

Otra de las acusaciones habituales (se hace a muchas maestras de Guadalajara) es la de confeccionar ropas para niños y milicianos con los ornamentos religiosos. Desde la FETE se organizaba y alentaba la confección de prendas y muchas maestras en sus descargos aluden que fueron obligadas a ello. Por tanto la afirmación del saqueo es otra suposición que no contribuirá a suavizar la opinión de la Comisión Depuradora ni la moverá a ser benevolente.

3. Actuación de las autoridades que acceden al poder con la implantación del nuevo Estado. La actuación de las autoridades locales después del conflicto fue variada. En un primer momento actuaron con dureza y contribuyeron con sus informes a la limpieza socio-política e ideológica que se estaba realizando en España. Con el paso del tiempo y conscientes, quizás, de la gravedad de sus acusaciones, algunos suavizaron su postura y aportaron nueva información que, aunque contradictoria, fue atribuida por el juez del Juzgado de Revisiones a los rencores generados por el conflicto y a la visión apasionada del primer momento. Algún maestro llegó a lograr su rehabilitación una vez cumplida la pena de prisión impuesta en Consejo de Guerra al ser juzgado por procedimiento sumarísimo.

27 A.G.A. Educación. Legajo 187. Depuración de maestros. Expediente de la maestra de Pinilla de Jadraque. Informe del párroco. 
El maestro de Padilla de Hita, después de haber sido sancionado con la separación definitiva, solicita varias veces la revisión que no le será admitida por el Juzgado de Revisiones hasta 1946. El Juez, alegará entonces que, tanto el alcalde como el cura (especialmente este último) procedieron con notoria pasión y falta de justicia contra el maestro al que en su entorno se considera un hombre de intachable conducta en el orden religioso, moral y político. Éste, aporta para la revisión nuevos datos que son tenidos en cuenta: estuvo amenazado de muerte por haber sido interventor del candidato de derechas en las elecciones 1936 y certificado de buena conducta y apoyo de los vecinos del pueblo.

La posibilidad de que el maestro pueda pedir la revisión de su expediente abrirá un paréntesis de esperanza en el duro proceso depurador. Éstos la solicitarán al Juzgado Superior de Revisiones el cual se encargará de decidir si procede o no, atendiendo a la nueva documentación presentada. Nuevas pruebas, nuevos avales y el paso del tiempo, lograrán que algunos maestros sean readmitidos. Otros no aceptarán la negativa y recurrirán una y otra vez alargando el proceso. El último expediente de Guadalajara (teniendo en cuenta que para consultarlo deben pasar cincuenta años de la última petición o resolución) se podrá abrir en el 2022.

\section{ARCHIVOS}

Archivo General de la Administración (A.G.A.)

Archivo del Ministerio de Educación (A.C.M.E.)

Archivo Histórico Nacional (A.H.N.)

\section{BIBLIOGRAFÍA}

Álvarez Oblanca, Wenceslao; La represión de la postguerra en León. Depuración de la Enseñanza (1936-1943), Edi. Santiago Garcia, León, 1986. BARREIRo RodRIGUEz, Herminio; Lorenzo Luzuriaga y la renovación educativa en España (1889-1936) Edicios do Castro, A Coruña (Pp. 86)

Crespo Redondo, Jesús; Purga de maestros en la Guerra Civil, Edi. Ámbito, Valladolid, 1987.

FERnÁNDEZ SORIA, J.; AgulLó, M. ${ }^{2}$ Carmen; Maestros valencianos bajo el franquismo. Edi. Alfons el Magnànim, Valencia, 1999. 
GonzÁlez AGAPITO, José; MARQUÉs y SUREDA, Salomó; La repressió del professorat a Catalunya sota el franquisme (1939-1943), Institut d'Estudis Catalans, Barcelona, 1997

Luís MARTín, Francisco; Historia de la FETE (1909-1936), Fondo de Enseñanza, 1997. (Pp. 30)

MIR, C.; CorRetgé, F.; J. Y. Sagués, J; Repressió económica y franquisme. L'actuació del Tribunal de Responsabilitats Polítiques a la provincia de Lleida, Publicacions de l'Abadía de Montserrat, Barcelona, 1997.

Morente VAlero, Francisco; La depuración del Magisterio Nacional (19361943) Edi. Ámbito, Valladolid, 1997.

REIG TAPIA, Alberto; Ideología e Historia (Sobre la represión franquista y la Guerra Civil) Akal, Madrid, 1986.

Usandizaga, Aranzazu; Ve y cuenta lo que pasó en España, Edi. Planeta. Barcelona, 2000. 